\title{
CÁC YẾU TỐ TÁC ĐộNG ĐẾN QUYẾT ĐỊNH MUA TRỰC TUYẾN SẢN PHẨM MAY MặC CỦA KHÁCH HÀNG TẠI TP. HỒ CHÍ MINH
}

\author{
TRÀ̀ THỊ HUẾ CHI \\ Truờng Đại học Công nghiệp thành phố Hồ Chi Minh; \\ tranthihuechi@iuh.edu.vn
}

Tóm tắt. Mua sắm trực tuyến sản phẩm may mặc ngày càng trở nên phổ biến ở Việt Nam và trên thế giới. Mục tiêu tổng quát của nghiên cứu này là nhằm khám phá các nhân tố tác động đển quyết định mua trực tuyến sản phẩm may mặc của người tiêu dùng tại thị trường thành phố Hồ Chí Minh. Thông qua kỹ thuật thảo luận nhóm và phương pháp nghiên cứu định lượng, kết quả khảo sát trực tiếp 488 khách hàng đã từng mua trực tuyến sản phẩm may mặc cho thấy có sáu yếu tố ảnh hưởng đến quyết định mua trực tuyến sản phẩm may mặc của khách hàng đó là: Chuẩn chủ quan của khách hàng, Thiết kế trang web, Nhận thức về sản phẩm may mặc trực tuyến, Sự tiện lợi của giao dịch trực tuyến, Tính tương tác khi giao dịch trực tuyến và Niềm tin của khách hàng. Đây cũng là căn cứ quan trọng để tác giả đề xuất những hàm ý quản trị và đóng góp những ý kiến, thông tin hữu ích cho các đối tượng có liên quan như doanh nghiệp kinh doanh thương mại điện tử và nhà sản xuất hàng may mặc.

Từ khóa. Quyết định mua trực tuyến, sản phẩm may mặc, khách hàng.

\section{FACTORS INFLUENCING ONLINE PURCHASE DECISION FOR APPAREL IN HO CHI MINH CITY}

\begin{abstract}
Shopping for clothes online is becoming increasingly common activities to Vietnamese consumers and the worldwide consumers. The objective of this research is to identify the factors influencing the online purchase decision for apparel products in Ho Chi Minh city. Through the focus group technique and quantitative research, data collected via the 488 interviews with questionnaire survey, the empirical findings indicate that the six factors influencing consumers to shop online decision are: Subjective norm, Website design, Perception for online apparel products, Usability of online buying, Interactivity of online buying, and Trust of customers. This study provides managerial implications for the e-commerce companies and the garment manufacturers.
\end{abstract}

Keywords. Online purchase decision, apparel, consumer.

\section{GIỚI THIỆ}

Theo số liệu công bố trong "Báo cáo thương mại điện tử Việt Nam năm 2016" của Cục Thương mại điện tử và Công nghệ thông tin (VECITA), doanh số thương mại điện tử B2C1 của Việt Nam ước đạt 5 tỷ USD, tăng hơn gấp đôi từ mức 2,2 tỷ USD của năm 2013, đặc biệt tăng kỷ lục so với mức doanh thu của năm 2012 ở mức chưa đầy 1 tỷ USD và chiếm 2,82\% tổng mức bán lẻ hàng hóa, dịch vụ cả nước năm 2016. Loại hàng hóa, dịch vụ được mua trực tuyến phổ biến nhất là quần áo, giầy dép và mỹ phẩm, chiếm khoảng $64 \%$ trên tổng số [1]. Thêm vào đó, theo báo cáo của Hiệp hội dệt may Việt Nam, ngoài vai trò quan trọng đối với nền kinh tế Việt Nam, ngành dệt may của Việt Nam cũng có vị trí quan trọng trên thị trường dệt may thế giới. Cụ thể, Việt Nam nằm trong top 5 quốc gia xuất khẩu dệt may lớn nhất thế giới năm 2015, chiếm 3,8\% tổng kim ngạch xuất khẩu dệt may toàn cầu; riêng tại Việt Nam kim ngạch xuất khẩu của ngành đạt 41,7 tỷ USD, chiếm $25,7 \%$ tổng kim ngạch xuất khẩu cả nước ${ }^{2}$. Ngành dệt may Việt Nam được dự báo sẽ có triển vọng tích cực trong thời gian tới, đặc biệt là với việc Việt Nam tham gia hội nhập ngày càng sâu rộng hơn vào nền kinh tế khu vực và kinh tế thế giới cũng sẽ tạo điều kiện cho các doanh nghiệp trong ngành tiếp cận thị trường tốt hơn. Tuy nhiên, khác với kinh doanh truyền thống, trong

${ }^{1}$ B2C (Business to Consumer): Giao dịch giữa các doanh nghiệp với các cá nhân.

${ }^{2}$ Nguồn: Hiệp hội Dệt may Việt Nam, http://www.vietnamtextile.org.vn/hiep-hoi-det-may-viet-nam-tien-hanh-hoi-nghi-tongket-nam-2016_p1_1-1_2-1_3-597_4-1858.html 
hoạt động kinh doanh trực tuyến hàng may mặc có một rào cản quan trọng đó là khách hàng không thể trực tiếp nhìn thấy và trực tiếp trải nghiệm được sản phẩm trước khi mua. Với thực tế đó, một vấn đề đặt ra là: Làm thế nào để tiếp cận, tạo lòng tin và thuyết phục khách hàng quyết định chọn mua sản phẩm may mặc thông qua các kênh phân phối trực tuyến?

Các nghiên cứu về "Hành vi mua hàng" nói chung và nghiên cứu về "Hành vi mua trực tuyến sản phẩm may mặc" nói riêng, được khá nhiều các nhà nghiên cứu thuộc trường phái nghiên cứu học hành vi, nghiên cứu tâm lý xã hội học tiến hành. Chúng được khởi đầu với những công trình nghiên cứu của Fishbein \& Ajzen [2] với tác phẩm "Giới thiệu lý thuyết và nghiên cứu về niềm tin, thái độ, ý định và hành vi mua", được xem là lý thuyết nền của trường phái này. Sau đó mô hình nghiên cứu này được cải tiến cũng bởi chính Ajzen [3] và tiếp nối bởi Davis [12]. Các mô hình lý thuyết cơ bản TRA, TPB, TAM, TPR, E-CAM ${ }^{3}$ của các nhà nghiên cứu trên được rất nhiều các tác giả trên toàn thế giới vận dụng để nghiên cứu hành vi tiêu dùng tại mỗi địa phương, quốc gia... Tuy nhiên, nghiên cứu quyết định mua trực tuyến sản phẩm may mặc của người tiêu dùng trên cơ sở kế thừa một cách hệ thống các lý thuyết và mô hình nghiên cứu của trường phái nghiên cứu tâm lý học hành vi chưa được xem xét trong bối cảnh cụ thể tại thành phố Hồ Chí Minh. Cho nên, nghiên cứu này đặt ra mục tiêu sẽ khai thác, tổng hợp một cách hệ thống các mô hình và lý thuyết về hành vi và quyết định mua sắm trực tuyến đã có trên thế giới và Việt Nam, sau đó kết hợp với các nghiên cứu đặc thù về ngành may mặc để khám phá sự tác động của các nhân tố ảnh hưởng đến quyết định mua trực tuyến sản phẩm may mặc của khách hàng tại thành phố Hồ Chí Minh. Phạm vi nghiên cứu của bài viết này sẽ tập trung vào hình thức $\mathrm{B} 2 \mathrm{C}$ (Business to Consumer), nghĩa là hoạt động thương mại được tiến hành bằng cách doanh nghiệp sẽ bán sản phẩm may mặc đến những khách hàng tiêu dùng thông qua mạng Internet hoặc các kênh giao dịch điện tử khác.

\section{CƠ SỞ LÝ THUYẾT VÀ CÁC GIẢ THUYẾT NGHIÊN CỨU}

\subsection{Các khái niệm về sản phẩm may mặc và quyết định mua trực tuyến}

Theo Hayes \& Jones [4], sản phẩm may mặc (apparel) là những sản phẩm thuộc ngành dệt may bao gồm các loại quần áo may sẵn nói chung và các phụ kiện kèm theo. Quần áo may sẵn (Ready-made clothing) là những quần áo được may theo những kích cỡ nhất định rồi bán trên thị trường. Chúng được vẽ mẫu và cắt may công nghiệp theo một số kích thước tiêu chuẩn định sẵn, cho số đông những người có kích thước tương đối giống nhau. Mỗi người, tùy thuộc vào chiều cao và cân nặng, sẽ có những số đo các vòng, số đo dài và số đo rộng khác nhau, do đó sẽ lựa chọn được những trang phục được sản xuất hàng loạt theo những cỡ số tương ứng với đặc điểm cơ thể mình [5].

Theo Solomon [6] quy trình quyết định mua của người tiêu dùng trải qua năm bước là: Nhận ra nhu cầu, tìm kiếm thông tin, xem xét các phương án, quyết định mua và đánh giá sau khi mua. Khách hàng sẽ có xu hướng khảo sát môi trường xung quanh và thu thập những dữ liệu thích hợp nhằm giúp đánh giá các phương án, các chọn lựa của mình và sẽ đưa ra một "quyết định mua" hợp lý đáp ứng mong muốn và nhu cầu đặc thù của chính họ. Quá trình hình thành nên quyết định mua của khách hàng đôi khi là một quá trình phức tạp và khách hàng phải dựa vào những thông tin về sản phẩm, dịch vụ, thương hiệu và những trải nghiệm mà họ đã thu nhận được trong quá khứ để đi tới quyết định mua hàng [7].

Quá trình ra quyết định mua sắm trực tuyến, về cơ bản cũng giống như quá trình mua thông thường, tuy nhiên trong quá trình này người tiêu dùng bị ảnh hưởng bởi nhiều yếu tố bên ngoài và bên trong [9]. Toàn bộ quá trình mua trực tuyến có thể đơn giản hóa thành hai giai đoạn chính: Thứ nhất là sàng lọc thông tin trục tuyến, cụ thể là khách hàng sẽ thông qua các công cụ tìm kiếm trên mạng (SEO Search Engine Optimization), các "từ khóa" (Key words) thích hợp để truy xuất các thông tin cần thiết liên quan đến sản phẩm, dịch vụ cần mua; Thư hai là quyết định mua trụcc tuyến, cụ thể là ở bước này thông qua những công cụ tương tác, người dùng sẽ thực hiện sự so sánh, đánh giá giữa các sản phẩm, dịch vụ đã sàng lọc ở giai đoạn đầu. Nghiên cứu của Constantinides [10] đã chỉ ra thực tế rằng việc đánh giá này sẽ dẫn khách hàng đến quyết định mua hàng, nếu sản phẩm đáp ứng được kỳ vọng của khách hàng thì họ sẽ hài lòng với việc mua hàng; còn nếu nó thấp hơn kỳ vọng thì người tiêu dùng sẽ có một nhận định tiêu cực về sản phẩm, dịch vụ. Điều đó nghĩa là, trong các hành vi mua hàng tiếp theo, khách hàng sẽ sử

${ }^{3}$ TRA, TPB: là các mô hình nghiên cứu cơ bản thuộc nhómThuyết hành động hợp lý; TAM: thuộc nhóm Thuyết chấp nhận công nghệ; TPR, E-CAM: thuộc nhóm Thuyết chấp nhận sử dụng thương mại điện tử. 
dụng những trải nghiệm này để ra quyết định sẽ mua hay không mua lặp lại sản phẩm, dịch vụ đó [8]. Như vậy, có thể thấy hành vi mua trực tuyến là quy trình không đơn giản, đặc biệt khi người dùng đang sống trong kỷ nguyên số, đứng trước vô vàn sự lựa chọn giữa các thương hiệu khác nhau, điều này khiến cho việc ra quyết định chọn lựa là rất khó khăn, khiến khách hàng phải đắn đo suy nghĩ và đánh giá các sự lựa chọn một cách kỹ càng hơn. Theo Constantinides [10], quyết định mua hàng trực tuyến là một hành động quyết định đã được thực hiện của khách hàng trong việc lựa chọn sản phẩm hay dịch vụ được cung cấp trên thị trường trực tuyến. Còn theo Osorno [9], quyết định mua trực tuyến của khách hàng là việc ra quyết định về việc chọn mua sản phẩm sau một khoảng thời gian xem xét về các thông tin trực tuyến thông qua các công cụ tìm kiếm trên mạng, sau đó đánh giá các phương án dự kiến và cuối cùng đưa ra sự lựa chọn mà khách hàng cho là đúng đắn nhất. Bài viết này sẽ sử dụng định nghĩa của Sanad [11]: “Quyết định mua trực tuyến sản phẩm may mặc (Online purchase decision for apparel) là quá trình suy nghĩ dẫn dắt người tiêu dùng đi từ bước xác định nhu cầu, phân tích các lựa chọn đển bước chọn mua một hoặc một số sản phẩm may mặc cụ thể thông qua môi trường Internet”.

\subsection{Mô hình lý thuyết}

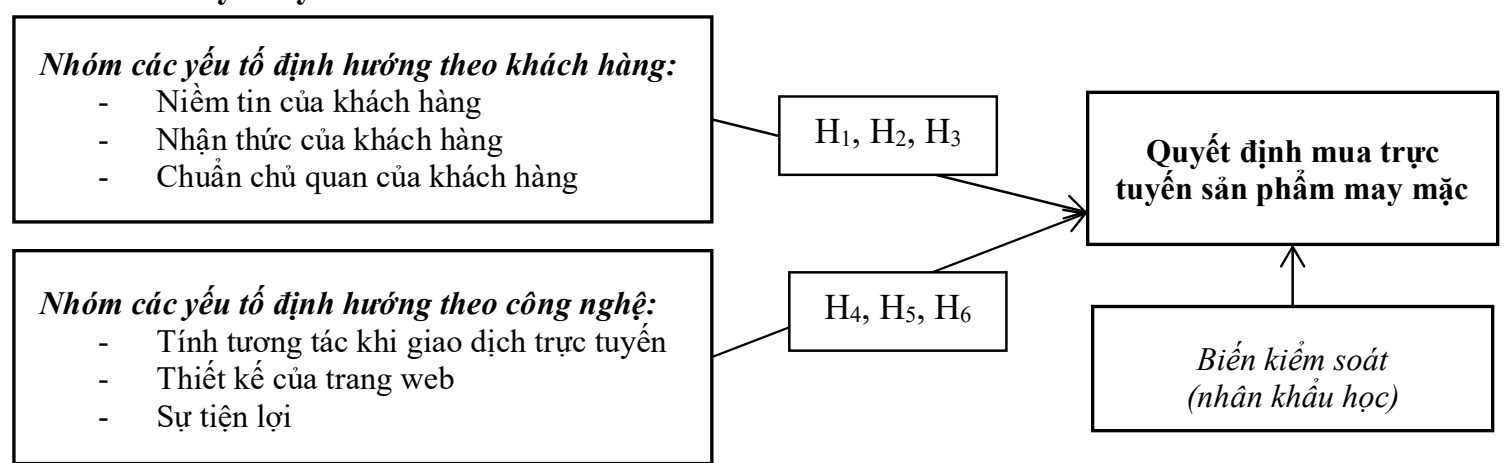

Hinh 1. Mô hình nghiên cứu đề xuất

Căn cứ vào phần tổng quan và hệ thống hóa các nhóm lý thuyết nghiên cứu về hành vi mua sắm trực tuyến (Bao gồm ba nhóm lý thuyết chính: Thuyết hành động hợp lý, Thuyết chấp nhận công nghệ và Thuyết chấp nhận giao dịch trực tuyến) và các nghiên cứu về việc tiêu dùng sản phẩm may mặc của nhiều tác giả như Fishbein và Ajzen [2], Ajzen (1991), Davis [12], Constantinides [10], Solomon [6], Coleman và các đồng sự [13], Nandini và Jeevananda [14], Osorno [9], Sanad [11]... đã cho thấy có rất nhiều yếu tố tác động đến quyết định mua trực tuyến của khách hàng với nhiều quan điểm tiếp cận khác nhau. Tuy nhiên để khái quát hóa và mô hình hóa vấn đề nghiên cứu, tác giả sẽ tiếp cận theo hai quan điểm nghiên cứu được chấp nhận phổ biến sau: Một là, quan điểm định hướng theo khách hàng (Consumer - Oriented Factors) là cách tiếp cận từ góc độ khách hàng, tập trung vào những nhận định của người tiêu dùng về mua sắm trực tuyến và thường được xem xét dưới góc độ nhân khẩu học của khách hàng [7]. Quan điểm này chú trọng nghiên cứu mối quan hệ giữa các yếu tố tâm lý, cá nhân của khách hàng đến hành vi mua trực tuyến của họ, bao gồm các yếu tố cơ bản là: Niềm tin của khách hàng; Các chuẩn chủ quan của khách hàng; Các nhận thức của khách hàng về sản phẩm may mặc. Hai là, quan điểm định hướng theo công nghệ (Technology- Oriented Factors) là cách tiếp cận từ các yếu tố công nghệ. Quan điểm này chú trọng vào việc dự đoán khả năng quyết định mua trực tuyến của khách hàng thông qua trải nghiệm về các nội dung, tính năng, thiết kế của trang web; các thao tác, quy trình thực hiện giao dịch trực tuyến, bao gồm các yếu tố cơ bản sau: Tính tương tác; Sự tiện lợi; Thiết kế website. Một số nghiên cứu tiêu biểu, của các tác giả Zhou và các đồng sự [7] được thực hiện ở Hoa Kỳ và của Lin [15] ở Đài Loan, đã cho thấy hai quan điểm trên không những không mâu thuẫn mà còn củng cố và hỗ trợ lẫn nhau, bởi vì sự thành công của thị trường thương mại điện tử phụ thuộc phần lớn vào sự sẵn lòng chấp nhận của người tiêu dùng. Từ đó, mô hình nghiên cứu lý thuyết được đề xuất bao gồm hai nhóm yếu tố và mồi nhóm bao gồm ba yếu tố như hình 1. 


\subsection{Các giả thuyết nghiên cứu}

\section{Niềm tin của khách hàng đối với mua sắm trục tuyến (Trust):}

Trong bối cảnh mua sắm trực tuyến, khái niệm niềm tin được hiểu là độ sẵn lòng chấp nhận tình trạng có thể bị rủi ro hoặc bị tổn thương của khách hàng từ việc giao dịch trực tuyến, sau khi khách hàng đã tìm hiểu về các nhà bán lẻ trực tuyến này [16]. Niềm tin là yếu tố trung tâm trong các mối quan hệ trao đổi, giao dịch trên thị trường và đặc biệt là trong môi trường giao dịch trực tuyến, vì ở bối cảnh này người mua không tiếp xúc trực tiếp được với người bán và món hàng cần mua sắm. Chen [17] đã nhận dạng được năm loại rủi ro điển hình trong hoạt động mua sắm trực tuyến như sau: Ngoài ba loại rủi ro thông thường của giao dịch kinh doanh truyền thống là rủi ro kinh tế, rủi ro xã hội và rủi ro thực hiện, thì giao dịch trực tuyến có thêm hai loại rủi ro mới là rủi ro cá nhân (khách hàng bị đánh cắp và lạm dụng thông tin thẻ tín dụng) và rủi ro về quyền riêng tư (khách hàng bị xâm phạm các thông tin cá nhân). Để giảm thiểu rủi ro và xây dựng lòng tin, các nhà bán lẻ trực tuyến cần phải đảm bảo trang web của họ là an toàn, đáng tin cậy và tôn trọng quyền riêng tư của khách hàng [18]. Điều này dẫn đến giả thuyết sau:

H1: Niềm tin của khách hàng và quyết định mua sắm trực tuyến có mối quan hệ cùng chiều với nhau.

\section{Nhận thức của khách hàng về sản phẩm may mặc (Product perception):}

Xét từ quan điểm của khách hàng, sản phẩm có thể chia thành hai nhóm là sản phẩm trải nghiệm và sản phẩm tìm kiếm [6], trong đó "Sản phẩm may mặc" thuộc nhóm "Sản phẩm trải nghiệm" (Experience goods) - là sản phẩm mà giá trị, chất lượng của chúng chỉ có thể thực sự xác định được bằng cách tiêu dùng hoặc sử dụng chúng. Như vậy, do tính chất đặc thù của quần áo may sẵn (ready-made clothing) nên các nhận thức của khách hàng về sản phẩm càng có ý nghĩa quan trọng đối với hành vi quyết định mua của họ [11]. Các nhà nghiên cứu Nandini và Jeevananda [14], Osorno [9], Sanad [11] nhận định rằng nhận thức của khách hàng về sản phẩm may mặc được mua trực tuyến chịu tác động bởi các thành tố marketing-mix như chính sách giá cả hợp lý, chất lượng sản phẩm được đảm bảo, mẫu mã sản phẩm đa dạng... và những nhận thức này là một tập hợp các lợi ích, giá trị, đặc trưng, tính thẩm mỹ của sản phẩm may mặc mang đến cho người tiêu dùng cảm xúc, cảm giác, sự thích thú và khơi dậy sự quan tâm của họ đối với sản phẩm đó. Từ những lập luận trên suy ra giả thuyết sau:

H2: Nhận thức của khách hàng và quyết định mua sắm trực tuyến có mối quan hệ cùng chiều với nhau.

\section{Chuẩn chủ quan của khách hàng (Subjective norm):}

Trong mô hình TRA và $\mathrm{TPB}^{4}$, khái niệm chuẩn chủ quan được hiểu là hệ thống các chuẩn mực, suy nghĩ, quan niệm và tư duy có tính chủ quan và logic của một cá nhân hay tập thể trong nhiều trường hợp và phạm vi không gian cụ thể nào đó [2], [3]. Chuẩn chủ quan là nhận thức của một người về việc hầu hết những người quan trọng đối với cá nhân này nghĩ là người đó nên hay không nên thực hiện một hành vi nào đó. Mức độ tác động của yếu tố chuẩn chủ quan phụ thuộc vào hai nhân tố là: Mức độ ủng hộ hoặc phản đối từ những người xung quanh, và Động cơ thúc đẩy làm theo mong muốn của những người có ảnh hưởng [2]. Còn các nghiên cứu thực nghiệm từ việc vận dụng hoặc mở rộng các mô hình của Thuyết hành động hợp lý cho thấy khách hàng có những kiến thức, kinh nghiệm giao dịch trực tuyến, khách hàng đã từng hài lòng khi mua online sẽ dễ dàng mua lại [19]; người chưa mua sẽ có xu hướng đọc những bài nhận xét hoặc bình luận của người có kinh nghiệm để đưa ra quyết định mua của mình [20]; một cá nhân trước khi quyết định mua sắm thường có xu hướng tham khảo thông tin từ các nhóm tham chiếu như người thân, bạn bè, đồng nghiệp, đặc biệt là những mặt hàng mang biểu tượng xã hội cao như sản phẩm may mặc thời trang [14]. Từ đó hình thành giả thuyêt:

H3: Chuẩn chủ quan tích cực của khách hàng và quyết định mua sắm trục tuyến có mối quan hệ cùng chiều với nhau.

\section{Tính tuơng tác khi giao dịch trục tuyến (Interactivity):}

Tính tương tác trong quyết định mua trực tuyến của khách hàng là sự tác động qua lại, có ảnh hưởng lẫn nhau giữa các đối tượng con người hoặc sự vật [8]. Tương tác là đặc điểm chính của công nghệ mới (còn gọi là thế hệ Web 2.0), đòi hỏi mô hình đa chiều trong hoạt động truyền thông, người dùng có thể chủ động tìm kiếm và lựa chọn thông tin chứ không đơn thuần nhận thông tin một chiều từ nhà mạng như truyền thống. Häubl \& Trifts [8] đã phân yếu tố tương tác thành hai nhóm chính là: Tính tương tác giữa

${ }^{4}$ TRA, TPB: Là các mô hình nghiên cứu cơ bản thuộc nhóm Lý thuyết Hành động hợp lý, trong đó TRA là Thuyết hành động hợp lý, TPB là Thuyết hành vi dự định. 
khách hàng với nhà bán lẻ trực tuyến (The user and the online vendor); và Tính tương tác giữa các khách hàng với nhau (The web users). Mối quan hệ tương tác hai chiều giữa người dùng và nhà kinh doanh trực tuyến thể hiện qua nhiều hoạt động như: Khả năng điều hướng của website nhanh chóng; Các gian hàng trực tuyến (E-stores) tạo cho khách hàng nhiều trải nghiệm web với mức độ cá nhân hóa cao; Khách hàng dề dàng kết nối với doanh nghiệp trực tuyến, tăng cường hoạt động quản trị quan hệ khách hàng trực tuyến (e-CRM - Electronic Customers Relationship Management) tốt [22]... Mối quan hệ tương tác giữa các người dùng với nhau thể hiện qua việc doanh nghiệp cung cấp trực tuyến cung cấp cho khách hàng quyền thiết lập liên lạc với các người sử dụng Internet khác; cung cấp cho họ cơ hội để củng cố việc nhận dạng thương hiệu, qua đó người mua sẽ giảm cảm giác không chắc chắn của việc mua trực tuyến và vì vậy, kỳ vọng họ sẽ dễ đi đến quyết định mua hàng hơn [10]. Như vậy, nếu doanh nghiệp phát huy các hoạt động tương tác với khách hàng và e-CRM tốt sẽ cung cấp cho khách hàng những trải nghiệm mua sắm tích cực và sẽ giúp củng cố, phát huy mối quan hệ tốt đẹp giữa người kinh doanh và người tiêu dùng Điều này giúp hình thành giả thuyết sau:

H4: Tính tuoong tác khi giao dịch trục tuyến và quyết định mua sắm trục tuyến có mối quan hệ cùng chiều với nhau.

Thiết kế của trang web (Web design):

Thiết kế của website là tổng hòa các yếu tố bao gồm màu sắc, cách sắp xếp nội dung và giao diện đồ họa tổng thể [25]; Thiết kế của website bao gồm nhiều phần khác nhau, nhưng quan trọng nhất là chất lượng trình bày và phong cách đặc trưng của website, điều này có được là do sự kết hợp các màu sắc, kiểu chữ, kích thước của phông chữ, hình ảnh động, hiệu ứng âm thanh, độ rõ nét và dễ đọc của văn bản [24]. Cách trình bày trực quan một cửa hàng ảo (E-store) là yếu tố mang tính "sống còn" đối với nhà bán lẻ trực tuyến để giúp định hình nhận thức của khách hàng [25]. Đặc biệt là trong hoạt động kinh doanh trực tuyến sản phẩm may mặc, một trong những trở ngại cơ bản mà người bán lẻ phải vượt qua đó là tạo nhận thức tích cực cho khách hàng trước khi mua hàng [11]. Nghiên cứu của Ha, Kwon, \& Lennon [26] gợi ý rằng các gian hàng trực tuyến thời trang nên cung cấp nhiều thông tin trực quan về sản phẩm với cách trình bày đa dạng, góc nhìn rộng, quan sát được tổng thể trang phục, cận cảnh các chi tiết, thấy được đầy đủ các mặt trước, mặt sau và có thể xoay $360^{\circ} \ldots$ để làm gia tăng ý định mua hàng của khách. Nghiển cứu của Cyr, Head và Larios [27] cho thấy rằng chất lượng hình ảnh tốt với màu sắc sản phẩm thực tế sẽ đặc biệt quan trọng đối với các sản phẩm mang tính biểu cảm như quần áo thời trang; việc sử dụng hình ảnh chuyển động sẽ làm tăng mức độ chú ý của khách hàng và giúp họ gia tăng nhận thức về sản phẩm, tạo thái độ tích cực với sản phẩm và sẽ góp phần làm quyết định mua hàng tăng lền. Lập luận này giúp đề xuất giả thuyết:

H5: Thiết kế của trang web và quyết định mua sắm trục tuyến có mối quan hệ cùng chiều với nhau.

\section{Sụ tiện lọi của giao dịch trục tuyến (Usability):}

Mô hình chấp nhận công nghệ TAM của Davis [12] đã cho thấy hai nhân tố quan trọng tác động đến sự chấp nhận sử dụng công nghệ của người dùng là biến "Nhận thức tính hữu ích" (PU) và biến "Nhận thức tính dễ sử dụng" (PEOU). Nội dung cơ bản của chúng đề cập đến cảm nhận của người sử dụng về mức độ mà hệ thống sẽ cải thiện kết quả công việc của họ $(\mathrm{PU})$ và mức độ nỗ lực cần có để sử dụng được hệ thống. Trong nghiên cứu của Guerrero và Román [28], tác giả nhóm chung hai nhân tố trên vào biến có tên gọi là "Sự tiện lợi" - được hiểu là các mức độ mà dịch vụ trực tuyến có thể đem đến cho người dùng để đạt được các mục tiêu mua sắm có hiệu quả và hài lòng trong một bối cảnh cụ thể. Nghiên cứu của Constantinides [10] tóm tắt các thành tố cơ bản của tính hữu dụng bao gồm: sự giao dịch thuận tiện, khả năng điều hướng của trang web, quy trình tìm kiếm, quá trình đặt hàng, giao hàng và thanh toán, tốc độ truy cập và khả năng tiếp cận trang web. Như vậy, có thể thấy yếu tố về tính tiện lợi phải được xem là một trong những yếu tố cơ bản của quyết định mua, đặc biệt là trong bối cảnh người tiêu dùng ngày càng có rất nhiều sự chọn lựa mua trực tuyến chỉ với một cú nhấp (click) chuột đơn giản. Như vậy, biển số "Sự tiện lợi" sẽ được đề xuất giả thuyết nghiên cứu sau:

H6: Yếu tố sụ tiện lợi và quyết định mua sắm trực tuyến có mối quan hệ cùng chiều với nhau. 


\section{PHƯONG PHÁP NGHIÊN CÚU}

\subsection{Quy trình và phương pháp nghiên cứu}

Đầu tiên, nghiên cứu sơ bộ được tiến hành bằng kỹ thuật thảo luận nhóm (Focus group), mục tiêu của hoạt động này là nhằm kiểm tra, sàng lọc và hiệu chỉnh mối quan hệ giữa các nhân tố trong mô hình nghiên cứu ở hình 1 . Đối tượng tham gia thảo luận nhóm bao gồm 10 người, là những khách hàng ở thành phố Hồ Chí Minh đã từng mua hàng may mặc trực tuyến, thành phần được lựa chọn nhằm đảm bảo tính đại diện của mẫu nghiên cứu về giới tính, độ tuổi, nghề nghiệp và trình độ học vấn. Kết quả cho thấy các đối tượng tham gia thảo luận đồng thuận với hai nhóm yếu tố ảnh hưởng đến quyết định mua hàng may mặc ở mô hình lý thuyết, tuy nhiên thứ tự sắp xếp các yếu tố trong mỗi nhóm có sự điều chỉnh như sau: Nhận thức của khách hàng về sản phẩm, Niềm tin của khách hàng, Chuẩn chủ quan của khách hàng, Thiết kế của website, Sự tiện lợi của giao dịch trực tuyến và Tính tương tác khi giao dịch trực tuyến.

Kế tiếp, nghiên cứu sơ bộ định lượng được thực hiện bằng kỹ thuật phỏng vấn trực tiếp 51 khách hàng đã từng mua trực tuyến sản phẩm may mặc, thông qua Bảng câu hỏi khảo sát sơ bộ với thang đo Likert 5 điểm. Mục đích của bước này là để chuẩn hóa các thuật ngữ và điều chỉnh, kiểm tra độ tin cậy của các thông tin. Kết quả xử lý bằng phần mềm SPSS đã cho thấy các thành phần của thang đo trong bảng câu hỏi đều đạt yêu cầu kiểm định độ tin cậy của thang đo, với hệ số tin cậy Cronbach's Alpha của các thang đo đều có giá trị lớn hơn 0,7 . Như vậy là các thang đo trong bảng câu hỏi đều đạt tiêu chuẩn tin cậy để thực hiện bước nghiên cứu chính thức.

Cuối cùng, nghiên cứu chính thức được thực hiện bằng phương pháp định lượng, thông qua Bảng câu hỏi khảo sát chính thức để phỏng vấn 488 khách hàng tại thành phố Hồ Chí Minh. Mục đích của bước này nhằm kiểm định lại các thang đo trong mô hình nghiên cứu, phân tích chi tiết các dữ liệu thu thập được, xác định mối tương quan của các nhân tố với nhau.

\subsection{Thang đo nghiên cứu}

Thang đo được sử dụng trong nghiên cứu này được đề xuất dựa trên cơ sở kế thừa lý thuyết nghiên cứu và được bổ sung, điều chỉnh cho phù hợp bối cảnh mua sắm trực tuyến tại thành phố Hồ Chí Minh. Kết quả tổng quan lý thuyết và thảo luận nhóm đã xác định có bảy khái niệm nghiên cứu là: Nhận thức của khách hàng về sản phẩm may mặc trực tuyến, ký hiệu là PER; Niềm tin của khách hàng, ký hiệu là TRS; Chuẩn chủ quan của khách hàng, ký hiệu là SJN; Thiết kế website, ký hiệu là WED; Sự tiện lợi của giao dịch trực tuyến, ký hiệu là UST; Tính tương tác khi giao dịch trực tuyến, ký hiệu là INT và Quyết định mua trực tuyến sản phẩm may mặc, ký hiệu là $\mathrm{OPD}$. Mỗi khái niệm nghiên cứu này được đo lường bởi một số biến quan sát (xem chi tiết ở Phu lục 1).

\section{3. Đặc tính của mẫu nghiên cứu}

Với kích thước mẫu nghiên cứu bao gồm 488 khách hàng đã từng mua trực tuyến sản phẩm may mặc, kết quả phân tích đã cho thấy các đặc tính chung của các khách hàng này như sau: Đa số khách hàng ở lứa tuổi thanh niên (nhóm tuổi từ 18 đến 33 tuổi, chiếm 364 người trên tổng số 488 mẫu, chiếm tỷ lệ $74,6 \%$ khách hàng được khảo sát) và tỷ lệ khách hàng là nữ giới mua trực tuyến hàng may mặc nhiều hơn khách hàng nam giới, ứng với tỷ lệ lần lượt là $63,3 \%$ và $36,7 \%$; Đa số họ có thói quen sử dụng Internet khá nhiều, từ 15 giờ đến 60 giờ sử dụng bình quân hàng tuần (chiếm tỷ lệ $70,9 \%$ ), thậm chí có $20,1 \%$ người sử dụng Internet trên 60 giờ mỗi tuần, nghĩa là mỗi ngày bình quân họ truy cập mạng hơn 8,5 giờ; Đa số họ mua hàng thời trang qua website trực tuyến của công ty thời trang chẳng hạn như Ivymoda.com.vn, Newnem.com; Viettien.com.vn... (chiếm 43,65\%) và qua các website bán lẻ trung gian chẳng hạn như Zalora.vn, Lazada.vn, Topmot.vn... (chiếm 41,8\%); Những nghề nghiệp mua trực tuyến nhiều là đối tượng học sinh - sinh viên, lao động có chuyên môn, lao động phổ thông và cấp quản lý; Các nhóm khách hàng có thu nhập ở các ngưỡng từ 5 đến dưới 10 triệu đồng, từ 10 đến 18 triệu đồng mua nhiều nhất (chiếm đến $28,5 \%$, và $26,8 \%$ ), kế tiếp là nhóm khách hàng có thu nhập dưới 5 triệu (chiếm $18,6 \%$ ) từ 18 triệu đồng đến dưới 32 triệu đồng (chiếm 17,8\%) và nhóm mua ít nhất là các khách hàng có thu nhập từ mức 32 triệu đồng trở lên. 


\section{PHÂN TÍCH DŨ̃ LIỆU VÀ KẾT QUẢ}

\subsection{Kiểm định thang đo}

Đầu tiên, kết quả xử lý SPSS cho bộ dữ liệu 488 mẫu khảo sát được trình bày ở bảng 1 cho thấy các thang đo có độ chính xác khá cao với hệ số Cronbach's Alpha đều lớn hơn 0,7 và đồng thời các hệ số tương quan biến tổng của các biến đo lường đều đạt chuẩn (là lớn hơn 0,3 ). Như vậy, các thang đo đều được chấp nhận và toàn bộ các biến quan sát ban đầu được giữ nguyên. Kết quả này thuận lợi cho việc tiến hành phân tích khám phá nhân tố ở bước tiếp theo.

Bảng 1. Kiểm định độ tin cậy Cronbach’s Alpha

\begin{tabular}{|l|l|l|c|}
\hline Mô hình & Mã hóa & \multicolumn{1}{|c|}{ Thang đo } & Cronbach's Alpha \\
\hline \multirow{4}{*}{ Biến X } & PER & Nhận thức về sản phẩm may mặc & 0,889 \\
\cline { 2 - 4 } & TRS & Niềm tin của khách hàng & 0,762 \\
\cline { 2 - 4 } & SJN & Chuẩn chủ quan của khách hàng & 0,813 \\
\cline { 2 - 4 } & WED & Thiết kế trang web & 0,820 \\
\cline { 2 - 4 } & UST & Sự tiện lợi & 0,808 \\
\cline { 2 - 4 } & INT & Tính tương tác & 0,843 \\
\hline Biến Y & OPD & Quyết định mua trực tuyến sản phẩm may mặc & 0,751 \\
\hline
\end{tabular}

Nguồn: Trich kết quả xủ lý SPSS

Kế tiếp, kỹ thuật phân tích nhân tố khám phá EFA cho các biến độc lập $(\mathrm{X})$ và biến phụ thuộc $(\mathrm{Y})$ được tiến hành. Kết quả xử lý SPSS (xem chi tiết ở Phụ luc $2 A$ và $2 B$ ) các điều kiện: Hệ số KMO (KaiserMeyer-Olkin) có giá trị nằm giữa mức 0,5 và 1 ; Đại lượng Bartlett có giá trị Sig nhỏ hơn 0,05 ; Tổng phương sai trích (Total Variance Explained) lớn hơn 50\%; Hệ số Eigenvalue (là chỉ số đại diện cho phần biến thiên được giải thích bởi mỗi nhân tố) lớn hơn 1; đã cho thấy các dữ liệu nghiên cứu hoàn toàn phù hợp với các thông số thống kê.

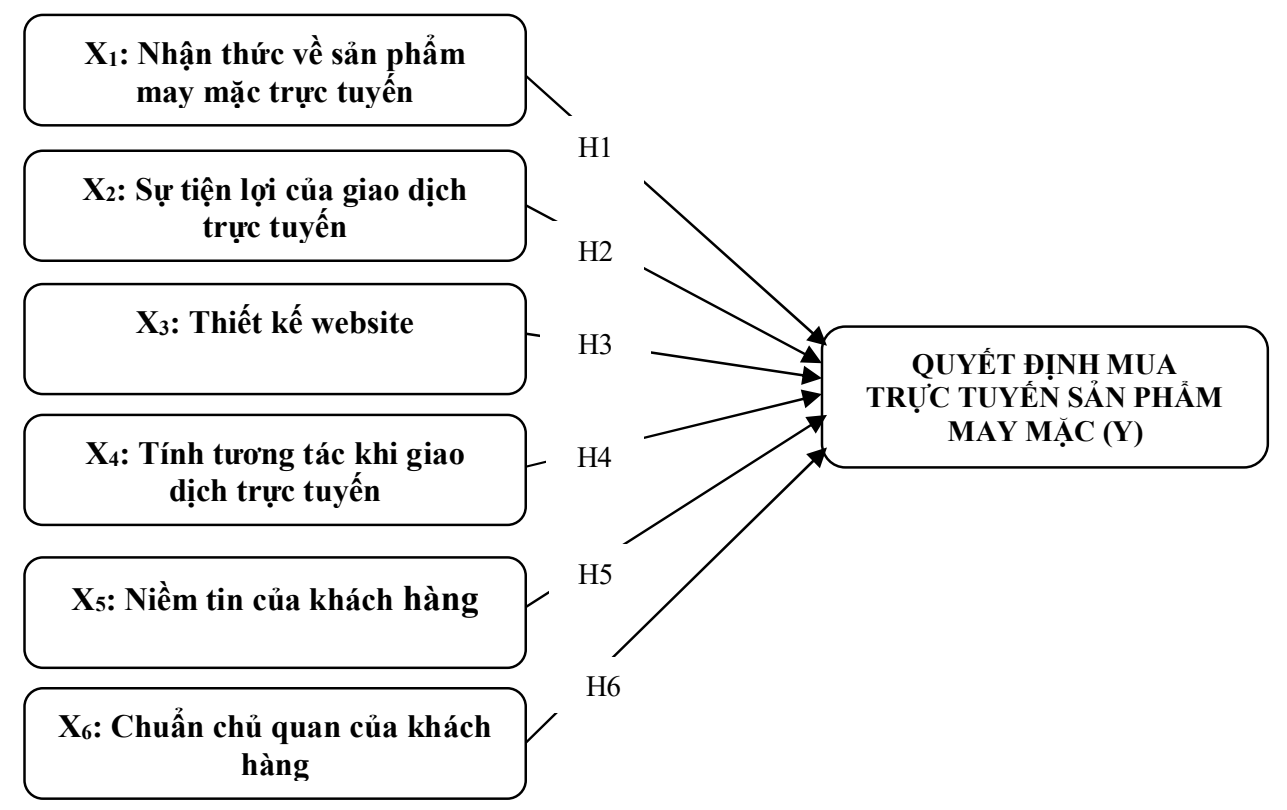

Hình 2. Mô hình nghiên cứu hiệu chỉnh sau phân tích EFA

Cuối cùng, với phương pháp tách nhân tố PCA (Principal Comonent Analysis), kết quả ma trận xoay nhân tố (Rotated Component Matrix) của các biến độc lập $\mathrm{X}$ và biến phụ thuộc $\mathrm{Y}$ đều cho thấy các hệ số tải nhân tố (Factor loading) đều lớn hơn 0,5 thỏa điều kiện và đảm bảo ý nghĩa thống kê, cho nên không có biến nào bị loại (xem chi tiết ở Phu luc $3 A$ và $3 B$ ). Như vậy, kết quả phân tích nhân tố cho thấy toàn bộ 
32 biến quan sát của các biến độc lập đã được hội tụ vào 6 nhân tố $\left(\mathrm{X}_{1}, \mathrm{X}_{2}, \mathrm{X}_{3}, \mathrm{X}_{4}, \mathrm{X}_{5}, \mathrm{X}_{6}\right)$ và 3 biến quan sát của biến phụ thuộc đã được hội tụ vào 1 nhân tố $\mathrm{Y}$ theo mô hình nghiên cứu được sắp xếp mới như hình 2.

Từ đó, các giả thuyết mới của mô hình nghiên cứu được đề xuất như sau: Giả thuyết $\mathrm{H}_{1}, \mathrm{H}_{2}, \mathrm{H}_{3}, \mathrm{H}_{4}$, $\mathrm{H}_{5}, \mathrm{H}_{6}$ lần lượt là các yếu tố "Nhận thức về sản phẩm", "Sự tiện lợi", "Thiết kế website", "Tính tương tác", "Niềm tin của khách hàng" và "Chuẩn chủ quan" sẽ ảnh hưởng tích cực đến "Quyết định mua trực tuyến sản phẩm may mặc" của khách hàng.

\subsection{Kiểm định giả thuyết}

Để kiểm định các giả thuyết nghiên cứu, quy trình thực hiện được tiến hành theo hai bước: Bước kiểm định mối tương quan giữa các nhân tố thông qua phân tích hệ số Pearson và bước phân tích hồi quy giữa các biến độc lập với biến phụ thuộc. Trước tiên, kết quả phân tích hệ số tương quan giữa các nhân tố thông qua phân tích hệ số Pearson (xem chi tiết ở Phu luc số 4) cho thấy: Biến phụ thuộc Y có tương quan thuận với các biến độc lập $\mathrm{X}$ vì hệ số tương quan đều dương, biến có tương quan mạnh nhất với $\mathrm{Y}$ là biến $\mathrm{X}_{6}(\mathrm{r}=0,673)$ và tương quan yếu nhất là biến nhất là biến $\mathrm{X}_{5}(\mathrm{r}=0,345)$; Mức kiểm định mối tương quan của các biến đều có $\operatorname{Sig}<0,05$, do vậy chúng có ý nghĩa về mặt thống kê. Kế tiếp là bước phân tích hồi quy giữa các biến độc lập với biến phụ thuộc: Với các thông số thống kê được trình bày trong Bảng 2 , kết quả đánh giá độ phù hợp của mô hình hồi quy cho thấy ở mức ý nghĩa $5 \%$, hệ số $\mathrm{R}^{2}$ hiệu chỉnh (Adjusted $\mathrm{R}$ Square) bằng 0,631 cho thấy độ phù hợp của mô hình là $63,1 \%$ hay nói cách khác, các biến độc lập giải thích được $63,1 \%$ sự biến thiên của biến phụ thuộc; Hệ số Durbin - Watson của mô hình bằng 1,909, với mức ý nghĩa $5 \%$, tham số $\mathrm{k}$ bằng 6 , tra bảng Durbin - Watson ta thấy $\mathrm{dU}<\mathrm{d}<4-\mathrm{dU}(1,831<1,909<4$ $-1,831=2,169)$, nên kết luận không có hiện tượng tương quan chuỗi bậc nhất trong mô hình. Đồng thời, kết quả phân tích ANOVA ở Bảng 3 cho thấy kết quả kiểm định $\mathrm{F}$ có giá trị Sig bằng $0,000(<0,05)$, nên đánh giá mô hình sử dụng là phù hợp.

Bảng 2. Bảng tóm tắt các thông số của mô hình

\begin{tabular}{|c|c|c|c|c|c|}
\hline Mô hình & $\mathrm{R}$ & $\mathrm{R}^{2}$ & $\mathrm{R}^{2}$ điều chỉnh & Sai số chuẩn đo lường & Durbin-Watson \\
\hline 1 & $.797^{\mathrm{a}}$ & .635 & .631 & .392 & 1.909 \\
\hline
\end{tabular}

Nguồn:Trích kết quả xủ lý SPSS

Bảng 4 cho thấy: Các hệ số Tolerance đều lớn hơn 0,0001 nên các biến đều đạt được tiêu chuẩn chấp nhận; Các hệ số phóng đại phương sai VIF đều nhỏ hơn 10 nên không có hiện tượng đa cộng tuyến; Hệ số Sig. của sáu biến độc lập đều nhỏ hơn 0,05 nên cả sáu biến này đều được chấp nhận. Đồng thời, các hệ số Beta đều lớn hơn 0 cho thấy các biến độc lập tác động thuận chiều với biến phụ thuộc. Nghĩa là khi tăng bất kỳ một nhân tố nào thì cũng sẽ làm cho quyết định mua trực tuyến sản phẩm may mặc tăng lên theo một tỷ lệ tương ứng. Kết quả phân tích này cho kết luận là tất cả các giả thuyết $\mathrm{H}_{1}, \mathrm{H}_{2}, \mathrm{H}_{3}, \mathrm{H}_{4}, \mathrm{H}_{5}, \mathrm{H}_{6}$ nêu trong mô hình ở Hình 2 đều được chấp nhận.

Bảng 3. Bảng tóm tắt các thông số của mô hình (ANOVA)

\begin{tabular}{|l|l|r|r|r|r|r|}
\hline \multicolumn{2}{|c|}{ Mô hình } & Tổng bình phương & Bậc tự do $(\mathrm{df})$ & Bình phương trung bình & $\mathrm{F}$ & Sig. \\
\hline \multirow{3}{*}{1} & Phần hồi quy & 128.688 & 6 & 21.448 & 139.526 & $.000^{\mathrm{b}}$ \\
& Phần dư & 73.940 & 481 & .154 & & \\
& Total & 202.628 & 487 & & & \\
\hline
\end{tabular}

Nguồn:Trích kết quả xủ lý SPSS 
Bảng 4. Bảng tóm tắt các thông số của mô hình

\begin{tabular}{|c|c|c|c|c|c|c|c|c|}
\hline \multirow{2}{*}{\multicolumn{2}{|c|}{$\begin{array}{l}\text { Model } \\
\text { (mô hình) }\end{array}$}} & \multicolumn{2}{|c|}{$\begin{array}{c}\text { HS Beta chưa chuẩn } \\
\text { hóa }\end{array}$} & \multirow{2}{*}{$\begin{array}{c}\text { Hệ số Beta chuẩn } \\
\text { hóa }\end{array}$} & \multirow[t]{2}{*}{$\mathrm{t}$} & \multirow[t]{2}{*}{ Sig. } & \multicolumn{2}{|c|}{$\begin{array}{c}\text { Thống kê đa cộng } \\
\text { tuyến }\end{array}$} \\
\hline & & B & Std. Error & & & & Tolerance & VIF \\
\hline & (Constant) & -.436 & .170 & & -2.571 & .010 & & \\
\hline & X1_PER & .181 & .034 & 0.193 & 5.368 & .000 & .587 & 1.703 \\
\hline & X2_UST & .220 & .039 & 0.179 & 5.675 & .000 & .760 & 1.316 \\
\hline 1 & X3_WED & .198 & .032 & 0.204 & 6.189 & .000 & .698 & 1.433 \\
\hline & X4_INT & .134 & .032 & 0.134 & 4.201 & .000 & .742 & 1.347 \\
\hline & X5_TRS & .126 & .036 & 0.105 & 3.494 & .001 & .846 & 1.181 \\
\hline & X6_SJN & .341 & .038 & 0.336 & 9.054 & .000 & .552 & 1.812 \\
\hline
\end{tabular}

Nguồn:Trích kết quả xủ lý SPSS

Như vậy, mối quan hệ giữa biến phụ thuộc quyết định mua trực tuyến sản phẩm may mặc $\mathrm{Y}$ và các biến độc lập $\mathrm{X}$ được thể hiện trong phương trình hồi quy đa biến như sau:

$$
Y=0,193 X_{1}+0,179 * X_{2}+0,204 * X_{3}+0,134 * X_{4}+0,105 * X_{5}+0,336 * X_{6}
$$

\subsection{Kiểm định các biến kiểm soát}

Để kiểm định sự khác biệt về quyết định mua trực tuyến sản phẩm may mặc giữa các khách hàng ở những nhóm giới tính, độ tuổi, trình độ học vấn, nghề nghiệp và thu nhập trung bình khác nhau, tác giả tiến hành phân tích Levene và ANOVA. Tổng hợp kết quả được trình bày trong Bảng 5 như sau:

Bảng 5. Bảng tóm tắt hệ số Levene và ANOVA

\begin{tabular}{|l|c|c|l|}
\hline \multicolumn{1}{|c|}{ Biến kiểm soát } & $\begin{array}{c}\text { Sig. } \\
\text { (phân tích Levene) }\end{array}$ & $\begin{array}{c}\text { Sig. } \\
\text { (phân tích ANOVA) }\end{array}$ & Nhận xét \\
\hline Giới tính & 0,302 & 0,000 & Có sự khác biệt giữa các nhóm khách hàng. \\
Độ tuồi & 0,087 & 0,000 & Có sự khác biệt giữa các nhóm khách hàng. \\
Trình độ học vấn & 0,332 & 0,000 & Có sự khác biệt giữa các nhóm khách hàng. \\
Nghề nghiệp & 0,376 & 0,000 & Có sự khác biệt giữa các nhóm khách hàng. \\
Thu nhập bình quân & $\mathbf{0 , 0 0 5}$ & - & Cần thêm kiểm định Tamhane. \\
\hline
\end{tabular}

Nguồn: Tổng hơp tù̀ kết quả xủ lý SPSS.

Theo kết quả Bảng 5 , bốn biến kiểm soát là Giới tính, Độ tuổi, Trình độ học vấn và Nghề nghiệp đều có mức ý nghĩa Sig của phân tích Levene lớn hơn 0,05 và mức ý nghĩa Sig của phân tích ANOVA bằng 0,000 (nhỏ hơn 0,05 ) nên kết luận, với độ tin cậy $95 \%$, có sự khác biệt về quyết định mua trực tuyến sản phẩm may mặc giữa các khách hàng thuộc các nhóm khác nhau về giới tính, độ tuổi, trình độ học vấn và nghề nghiệp.

Riêng với biến kiểm soát Thu nhập bình quân, do kết quả phân tích Levene có mức ý nghĩa Sig nhỏ hơn $0,05(0,005<0,05)$ nên phải sử dụng kỹ thuật phân tích sâu ANOVA (kiểm định Tamhane) (xem chi ti dụng kỹ thuật . Kết quả kiểm định Tamhane cũng đã cho thấy có nhiều cặp so sánh về giá trị trung bình của các nhóm thu nhập có sự khác biệt nhau và có ý nghĩa thống kê ở độ tin cậy 0,05 vì có giá trị mức ý nghĩa Sig nhỏ hơn 0,005 . Như vậy, với độ tin cậy $95 \%$, kết luận rằng có sự khác biệt về quyết định mua trực tuyến sản phẩm may mặc giữa các nhóm khách hàng có thu nhập trung bình khác nhau.

\section{THẢO LUẬN KẾT QUẢ VÀ HÀM Ý QUẢN TRI}

\subsection{Thảo luận kết quả nghiên cứu}

Mô hình nghiên cứu của đề tài này được xây dựng dựa trên hai quan điểm tiếp cận - đó là tiếp cận từ phía khách hàng và từ góc độ công nghệ. Đây là hai phương thức tiếp cận mới và mang tính hệ thống, 
chúng không những không mâu thuẫn mà còn củng cố và hỗ trợ lẫn nhau. Dựa vào việc hệ thống hóa các lý thuyết có liên quan và kết hợp với bước thảo luận nhóm và lấy ý kiến chuyên gia, tác giả đã xây dựng được bộ thang đo hoàn chỉnh cho các biến độc lập và biến phụ thuộc của mô hình nghiên cứu lý thuyết với tổng cộng 35 biến quan sát, trong đó một số biến quan sát có tính cập nhật xu hướng tiếp cận người tiêu dùng trong thời đại phát triển công nghệ số và mạng xã hội, chẳng hạn như: Website bán hàng trực tuyến sử dụng các hiệu ứng hỗ trợ tốt cho sản phẩm; Website bán hàng trực tuyến có nhiều từ khóa giúp khách hàng dễ dàng tìm kiếm và truy cập thông tin; Website bán hàng trực tuyến cung cấp cho khách hàng trải nghiệm web với mức độ cá nhân hóa cao...

\subsection{Các hàm ý quản trị}

Các kết quả nghiên cứu định lượng được kiểm định trên mẫu 488 khách hàng đã giúp tác giả đề xuất một số hàm ý cho các đối tượng có liên quan như nhà kinh doanh trực tuyến, nhà sản xuất sản phẩm thời trang. Cụ thể như sau:

\section{Hàm ý đối với nhà kinh doanh trực tuyến:}

Theo kết quả phân tích định lượng, "Chuẩn chủ quan của khách hàng” là nhân tố có ảnh hưởng lớn nhất đến "Quyết định mua trực tuyến sản phẩm may mặc". Điều này gợi ý cho các nhà bán lẻ trực tuyến phải am hiểu cách thức mà người tiêu dùng chịu ảnh hưởng và sử dụng các đánh giá trực tuyến của những người dùng khác trước khi quyết định mua sắm. Một số gợi ý đề xuất cho nhà kinh doanh trực tuyến để giảm thiểu những nhận xét tiêu cực của khách hàng đó là: Đáp ứng kịp thời, nghĩa là khi phát hiện có một đánh giá tiêu cực, doanh nghiệp cần phải phản hồi lại ngay theo hướng chủ động, cầu thị và tuyệt đối tôn trọng khách hàng (không phủ định lỗi, đẩy cái sai về phía khách hàng); Nếu nhận thấy khách hàng có sai sót, hiểu lầm trong nhận xét của họ, doanh nghiệp cần phải giải thích, đính chính kịp thời để khách hàng hiểu và điều chỉnh lại những nhận xét; Đồng thời, tích cực khuyến khích những khách hàng thân thiết, trung thành của doanh nghiệp đưa ra các ý kiến tốt và thậm chí doanh nghiệp còn cần chủ động tác động hình thành chuẩn chủ quan tích cực của khách hàng thông qua nhiều hoạt động trực tiếp và gián tiếp, chẳng hạn như: Tích cực sử dụng các phương tiện xã hội để tạo dựng và khuếch trương uy tín và danh tiếng

Đối với nhân tố "Thiết kế website", là nhân tố có ảnh hưởng lớn thứ nhì đến "Quyết định mua trực tuyến sản phẩm may mặc", nghiên cứu của KPMG International ${ }^{5}$ cũng đã cho thấy rằng các khách hàng hiện đại rất quan tâm đến chất lượng website khi mua sắm trên thị trường. Như vậy, để thúc đẩy quyết định mua trực tuyến của khách hàng, doanh nghiệp cần đầu tư thiết kế website bán hàng có giao diện, cấu trúc đơn giản và thân thiện với người dùng, nhưng đồng thời phải hấp dẫn, thu hút sự chú ý của khách hàng. Bên cạnh đó, website phải hỗ trợ các công cụ tìm kiểm, so sánh các sản phẩm với nhau; sử dụng đa dạng các hiệu ứng như âm thanh, hình ảnh xoay $360^{\circ}$, phòng thử đồ trực tuyến... để giúp khách hàng có thể hình dung rõ nét nhất về sản phẩm và nhanh chóng tìm ra được trang phục nào thỏa mãn tốt nhất nhu cầu của họ.

"Sự tiện lợi của giao dịch trực tuyến" là nhân tố có ảnh hưởng khá lớn đến quyết định mua trực tuyến của khách hàng. Trước tiên, nhà bán lẻ trực tuyến cần cải tiến và hoàn thiện các quy trình giao dịch với khách hàng. Đối với hoạt động mua hàng, cần cải tiến quy trình đặt hàng thật đơn giản và gọn nhẹ, khách hàng chỉ cần nhấp chuột (click) một lần vào sản phẩm họ lựa chọn và cái nhấp chuột thứ hai để điền những thông tin tối thiểu cần thiết là hoàn tất quy trình. Đối với hoạt động giao nhận hàng hóa, doanh nghiệp cần minh bạch quy trình giao hàng hóa cho khách hàng và đồng thời công bố chi phí giao hàng càng sớm càng tốt trong quá trình mua sắm. Các công ty cũng phải nỗ lực đưa ra nhiều tùy chọn giao hàng linh hoạt để khách hàng chọn phương thức phù hợp và tiện lợi với mình nhất. Đối với hoạt động đổi trả hàng hóa, đây là một trong những lý do quan trọng khiến người mua sắm sản phẩm may mặc trực tuyến rời bỏ giỏ hàng của họ nếu công ty bán hàng thiếu thông tin về chính sách bảo hành và đổi trả sản phẩm. Đối với hoạt động thanh toán, doanh nghiệp càng đa dạng hóa hình thức thanh toán sẽ càng tạo sự tiện lợi cho khách hàng, cụ thể là: thanh toán bằng tiền mặt khi khách hàng nhận được sản phẩm

\footnotetext{
${ }^{5}$ Nguồn: Báo cáo chuyên đề về hành vi và sở thích mua hàng trực tuyến do KPMG International thực hiện vào tháng 01/2017, https://home.kpmg.com/vn/vi/home/an-pham/2017/01/ mua-sam-truc-tuyen.html
} 
(phương thức COD - Cash on delivery); thanh toán trực tuyến bằng ví điện tử, thẻ ghi nợ nội địa hay thẻ tín dụng hoặc ghi nợ quốc tế; chuyển khoản qua ngân hàng...

Hai nhân tố "Tính tương tác khi giao dịch trực tuyến" và nhân tố "Niềm tin của khách hàng" tuy chỉ có hệ số tác động lần lượt là 0,134 và 0,105 đến "Quyết định mua trực tuyến sản phẩm may mặc" nhưng cũng là những nhân tố gây ảnh hưởng đến quyết định mua của khách hàng. "Tính tương tác" trong giao dịch trực tuyến có hai chiều chính, đó là: (1) Tương tác giữa khách hàng (The user) với nhà bán lẻ trực tuyến (The online vendor); và (2) Tương tác giữa các khách hàng với nhau (The web users). Để gia tăng chiều tương tác giữa khách hàng và nhà bán lẻ trực tuyến, doanh nghiệp cần: Cải thiện khả năng điều hướng của website; Các cửa hàng ảo (E-stores) phải cung cấp cho khách hàng những trải nghiệm web với mức độ cá nhân hóa (tính tùy biến sản phẩm) cao; Và đặc biệt để làm khách hàng hài lòng và lưu giữ lòng trung thành của họ, nhà bán lẻ trực tuyến phải thiết lập hoạt động quản trị quan hệ khách hàng trực tuyến (e-CRM - Electronic Customers Relationship Management) tốt. Để gia tăng chiều tương tác giữa các khách hàng với nhau, các doanh nghiệp cần phải biết khai thác sức mạnh của các ứng dụng trên nền tảng Web 2.0 như blog, mạng xã hội, các diễn đàn của người dùng (user's forum), phòng trò chuyện (chatroom)... và cung cấp cho khách hàng quyền thiết lập liên lạc với các người sử dụng Internet khác. Đối với việc tạo dựng và củng cố "Niềm tin của khách hàng" trong bối cảnh kinh doanh trực tuyến - khi người mua không thể tiếp xúc trực tiếp với người bán cũng như trang phục mà họ dự định mua - đòi hỏi doanh nghiệp không chỉ dừng lại ở mức cam kết về chất lượng hàng hóa có nguồn gốc, xuất xứ rõ ràng, có thương hiệu... mà nhà kinh doanh còn phải chú trọng cải tiến các hoạt động dịch vụ hỗ trợ khác như: rút ngắn thời gian giao hàng, cam kết bồi thường cho khách nếu giao hàng trễ, giảm thiểu các phiền phức, gây khó khăn cho khách khi giải quyết bồi thường, khiếu nại...

\section{Hàm ý đối với nhà sản xuất sản phẩm may mặc thời trang:}

Kết quả nghiên cứu đã cho thấy ngoài nhân tố đặc thù là "Nhận thức của khách hàng đối với sản phẩm may mặc" tác động đến quyết định mua, thì các đặc tính chung về hành vi mua và các yếu tố nhân khẩu học của các khách hàng đã từng mua sắm trực tuyến cũng là những thông tin quan trọng mà nhà sản xuất cần lưu ý. Thứ nhất, doanh nghiệp cần gia tăng nhận thức tích cực của khách hàng đối với sản phẩm may mặc. Do sản phẩm may mặc được xếp vào nhóm hàng hóa trải nghiệm ${ }^{6}$, cho nên những "Nhận thức của khách hàng đối với sản phẩm may mặc" được hình thành trước trong tâm trí khách hàng có ý nghĩa quan trọng đối với quyết định mua của họ. Điều này đòi hỏi các nhà sản xuất hàng thời trang cần tìm hiểu thật kỹ các nhận thức của khách hàng về sản phẩm may mặc được mua qua mạng, chẳng hạn như: Chính sách giá cả (giá sản phẩm, chi phí vận chuyển, chi phí giao dịch...); Chất lượng sản phẩm (chất liệu, màu sắc, nguồn gốc, xuất xứ...). Nhà kinh doanh sẽ làm tốt được việc này thông qua các chính sách marketing hiện đại, tiển hành nghiên cứu, khảo sát thị trường, tìm hiểu rõ nhu cầu, thị hiếu khách hàng, cũng như tiếp cận và cập nhật xu hướng thời trang của thế giới. Bên cạnh đó, chiến lược xây dựng và tạo dựng thương hiệu mạnh cũng sẽ góp phần quan trọng để tạo dựng uy tín, niềm tin và danh tiếng của doanh nghiệp trong mắt của khách hàng. Thứ hai, các tác động dựa trên những đặc tính chung về hành vi mua và các yếu tố nhân khẩu học của khách hàng. Kết quả phân tích ở mục 3.3 cho thấy, đối tượng khách hàng đã từng mua sắm trực tuyến sản phẩm may mặc tại thành phố Hồ Chi Minh chiếm nhiều nhất là nhóm tuổi thanh niên, họ có thói quen sử dụng Internet khá nhiều và có thu nhập bình quân ở mức trung bình thấp (từ dưới 5 triệu đồng và từ 5 đến dưới 10 triệu đồng). Điều này gợi mở một hướng phát triển dòng sản phẩm thời trang bình dân (Fast-fashion) hay còn gọi là thời trang giá rẻ, thời trang mì ăn liền - một hướng đi không hề mới đối với thị trường thế giới nhưng chưa định hình rõ nét ở Việt Nam. Thời trang "ăn liền" đánh mạnh vào tâm lý của giới trẻ hiện nay, thích diện những món đồ mốt nhất giống như trên các sàn diễn thời trang của thế giới nhưng lại không phải tốn quá nhiều chi phí để mua hàng hiệu thực sự, giúp cho những khách hàng giới bình dân cũng có thể mua được. Hiện tại, ngành kinh doanh thời trang bình dân đã có những phát triển vô cùng đáng kể và đang "làm mưa làm gió" trong làng mốt thế giới khi sở hữu thị trường khách hàng rộng lớn, với những thương hiệu mạnh như Zara (đã khai trương ở Tây Ban Nha từ năm 1975), H\&M (đã khai trương ở Thụy Điển từ năm 1947)... Như vậy, các nhà sản xuất may

\footnotetext{
${ }^{6}$ Hàng hóa trải nghiệm (Experience-goods) là những sản phẩm mà giá trị của chúng chỉ có thể thực sự xác định được bằng cách tiêu dùng hoặc sử dụng chúng. Nội dung này đã được trình bày chi tiết trong chương 2.
} 
mặc tại Việt Nam hoàn toàn có thể nghiên cứu và tiếp cận theo chiến lược phát triển này với một thị trường tiềm năng rộng mở.

\section{HẠN CHẾ VÀ HƯỚNG NGHIÊN CÚUU TIẾP THEO}

Mặc dù đã đạt được những kết quả nhất định, nhưng do một số yếu tố chủ quan và khách quan, nghiên cứu này vần tồn tại một số hạn chế. Thứ nhất, nghiên cứu này chỉ được khảo sát lấy mẫu trong phạm vi thị trường thành phố Hồ Chí Minh mà chưa có điều kiện áp dụng cho các địa phương khác, cho nên khả năng tổng quát hóa kết quả nghiên cứu chưa cao. Thứ hai, việc xây dựng mô hình lý thuyết và kiểm định được thực hiện trên thị trường $\mathrm{B} 2 \mathrm{C}$ (Business to Consumer - Giao dịch trực tuyến giữa doanh nghiệp và người tiêu dùng) trong khi trên thực tế hiện nay hoạt động mua bán trực tuyến đã phát triển rầm rộ với rất nhiều hình thức khác như B2B (Business to Business - Giao dịch giữa các doanh nghiệp với nhau), $\mathrm{C} 2 \mathrm{C}$ (Consumer to Consumer - Giao dịch giữa các cá nhân với nhau)... Những hạn chế này đã mở ra rất nhiều hướng cho các nghiên cứu tiếp theo trong tương lai, đặc biệt là dành cho những nhà nghiên cứu về hành vi tiêu dùng trực tuyến trong lĩnh vực bán lẻ ở một thị trường giàu tiềm năng phát triển như Việt Nam hiện nay.

\section{TÀI LIỆ THAM KHẢO}

[1] VECITA, "Báo cáo thương mại điện tử Việt Nam năm 2016," Bộ Công thương, Hà Nội, 2016.

[2] M. Fishbein and I. Ajzen, Belief, Attitude, Intention, and Behavior: An Introduction to Theory and Research, MA: Addison-Wesley, 1975.

[3] I. Ajzen, "The theory of planned behavior," in Organizational behavior and human decision processes, 50(2), 1991.

[4] S. G. Hayes and N. Jones, "Fast fashion: a financial snapshot," Journal of Fashion Marketing and Management: An International Journal, 10(3), pp. 282-300, 2006.

[5] Y. Kawamura, Doing research in fashion and dress: An introduction to qualitative methods, Berg, 2011.

[6] M. R. Solomon, Consumer Behavior: Buying, Having, and Being, Pearson/Prentice Hall, 2004.

[7] L. Zhou, L. Dai and D. Zhang, "Online shopping acceptance model-A critical survey of consumer factors in online shopping," Journal of Electronic commerce research, 8(1), pp. 41-61, 2007.

[8] G. Häubl and V. Trifts, "Consumer decision making in online shopping environments: The effects of interactive decision aids," Marketing science, 19(1), pp. 4-21, 2000.

[9] S. C. Osorno, "Consumer behaviour towards the fashion industry: What provoke planned or impulsive purchase?," Information Technology and Management, 4, pp. 303-318, 2014.

[10] E. Constantinides, "Influencing the online consumer's behaviour: The web experiences," Internet Research, Vol 14, pp. 111-116, 2004.

[11] R. Sanad, "Consumer Attitude and Purchase Decision towards Textiles and Apparel Products," World Journal of Textile Engineering and Technology, pp. 16-30, 2016.

[12] F. Davis, "Perceived usefulness, perceived ease of use, and user acceptance of information technology," MIS quarterly, pp. 319-340, 1989.

[13] L. J. Coleman, N. Bahnan and M. \&. C. N. Kelkar, "Walking the walk: how the theory of reasoned action explains adult and student intentions to go green," Journal of Applied Business Research, pp. 27(3), 165-181, 
2011.

[14] R. Nandini and S. Jeevananda, "To Study the Factors of Consumer Involvement in Fashion Clothing," International Journal of Science and Research (IJSR), Vol.3 (7), pp. 9-13, 2014.

[15] H. F. Lin, "Predicting consumer intentions to shop online: An empirical test of competing theories," Electronic Commerce Research and Applications, 6(4), pp. 433-442, 2008.

[16] D. H. McKnight, V. Choudhury and C. Kacmar, "The impact of initial consumer trust on intentions to transact with a web site: a trust building model," The Journal of Strategic Information Systems, 11(3), pp. 297-323, 2002.

[17] L. Chen, "The influence of social media on consumer behavior: An empirical study on factors influencing consumer purchase intention in China under the social media context," Aarhus University, Aarhus (Denmark), 2014.

[18] K. Cuneyt and B. Gautam, "The impacts of quickness, price, payment, risk, and delivery issues on on-line shopping," Journal of Socio-Economics, pp. 75-82, 2004.

[19] D. Ribbink and R. Van, "Comfort your online customer: quality, trust and loyalty on the internet," Managing Service Quality: An International Journal, pp. 446-456, 2004.

[20] N. Ellison, C. Steinfield and C. Lampe, "The benefits of Facebook "friends:" Social capital and college students' use of online social network sites," Journal of Computer-Mediated Communication, p. 12 (3), 2007.

[21] Q. Ye, R. Law, B. Gu and W. Chen, "The influence of user-generated content on traveler behavior: An empirical investigation on the effects of e-word-of-mouth to hotel online bookings," Computers in Human Behavior, 27(2), pp. 634-639, 2011.

[22] L. Jiang, M. Jun and Z. Yang, "Customer-perceived value and loyalty: how do key service quality dimensions matter in the context of B2C e-commerce?," Service Business, 10(2), pp. 301-317, 2016.

[23] R. S. Keshvari, "The Impact of E-CRM on Customers Attitude and Its Association with Generating Competitive Advantages in Iranian Financial B2B Context," International Business Research, 5(4), pp. 34-40, 2012.

[24] D. E. Rosen and E. Purinton, "Website design: Viewing the web as a cognitive landscape," Journal of Business Research, 57(7), pp. 787-794, 2004.

[25] T. Porat, R. Liss and N. Tractinsky, "E-stores design: The influence of e-store design and product type on consumers' emotions and attitudes," Human-Computer Interaction. HCI Applications and Services, pp. 712$721,2007$.

[26] Y. Ha, W. S. Kwon and S. J. Lennon, "Online visual merchandising (VMD) of apparel web sites," Journal of Fashion Marketing and Management: An International Journal, 11(4), pp. 477-493, 2007.

[27] D. Cyr, M. Head and H. Larios, "Colour appeal in website design within and across cultures: A multi-method evaluation," International journal of human-computer studies, 68(1), pp. 1-21, 2010.

[28] M. Guerrero and M. Román, "Characterization of online shoppers with navigation problems," Direct Marketing: an international journal, 1(2), pp. 102-113, 2007. 
[29] Đ. T. Nguyễn, Phương pháp nghiên cứu khoa học trong kinh doanh, Hồ Chí Minh: Tài Chính, 2011.

[30] R. Sanad, "Consumer Attitude and Purchase Decision towards Textiles and Apparel Products," World Journal of Textile Engineering and Technology, Vol.2, pp. 16-30, 2016.

[31] McKnight D. H., Choudhury H., Kacmar C., "Developing and Validating Trust Measures for e-Commerce: An Integrative Typology," Information systems research, pp. 334-359, 2002.

[32] C. M. Chiu, C. C. Chang, H. L. Cheng and Y. H. Fang, "Determinants of customer repurchase intention in online shopping," Online information review, 33(4), pp. 761-784, 2009.

[33] R. A. Bauer, "Consumer behaviour ask risk taking, risk taking and information handling in consumer behaviour.," Graduate School of Business Administration, pp. 23-34, 1967.

[34] D. Lee, J. Park and J. H. \& Ahn, "On the explanation of factors affecting e-commerce adoption," in ICIS 2001 Proceedings, 2001.

[35] C. P. Nielsen and K. Anderson, "Global market effects of alternative European responses to genetically modified organisms," in Review of world economics, 137(2), 2001.

[36] F. Davis, "A technology acceptance model for empirically testing new end-user information systems: Theory and results," Doctoral dissertation, Massachusetts Institute of Technology., USA, 1985.

[37] B. Williams, A. Onsman and T. Brown, "Exploratory factor analysis: A five-step guide for novices," Australasian Journal of Paramedicine, 8(3), pp. 1-13, 2010.

[38] P. Aspers and F. Godart, "Sociology of fashion: Order and change," Annual Review of Sociology, 39, 171192., 2013.

[39] D. W. Gerbing and J. C. Anderson, "An Updated Paradigm for Scale Development Incorporating Unidimesionality and Its Assessment.," Journal of Marketing Research, vol. 25, pp. 186-192, 1988.

[40] C. F. T. M. B. Dennis, E-Retailing, Oxon: Routeledge, 2004.

Ngày nhận bài: 16/10/2017 Ngày chấp nhận đăng: 19/12/2017 


\section{PHẦN PHỤ LỤC}

\section{PHỤ LỤC 1: THÀNH PHẦ THANG ĐO CÁC KHÁI NIỆM NGHIÊN CỨU}

\begin{tabular}{|c|c|c|}
\hline Nhân tố & Ký hiệu - Biến quan sát & Nguồn \\
\hline $\begin{array}{l}\text { Nhận thức của khách } \\
\text { hàng về sản phẩm } \\
\text { may mặc trực tuyến } \\
\text { (Perception) }\end{array}$ & $\begin{array}{l}\text { PER1. Sản phẩm may mặc trên mạng có kiểu dáng, màu sắc rất } \\
\text { phong phú } \\
\text { PER2. Sản phẩm may mặc trên mạng có đầy đủ các kích cỡ cơ } \\
\text { bản } \\
\text { PER3. Sản phẩm may mặc trên mạng có chất liệu phù hợp } \\
\text { PER4. Sản phẩm may mặc trên mạng có nguồn gốc xuất xứ, } \\
\text { thương hiệu rõ ràng } \\
\text { PER5. Sản phẩm may mặc mua trên mạng có giá cả hợp lý so } \\
\text { với mua tại cửa hàng thực tế } \\
\text { PER6. Sản phẩm may mặc trên mạng luôn sẵn có }\end{array}$ & $\begin{array}{l}\text { Nandini \& Jeevananda } \\
{[14] .} \\
\text { Sanad [30]. } \\
\text { Tự phát triển. }\end{array}$ \\
\hline $\begin{array}{l}\text { Niềm tin của khách } \\
\text { hàng đối với mua sắm } \\
\text { trực tuyến (Trust) }\end{array}$ & $\begin{array}{l}\text { TRS1. Thông tin cá nhân được bảo mật } \\
\text { TRS2. Thanh toán trực tuyến an toàn } \\
\text { TRS3. Thông tin về sản phẩm may mặc trên trang web đáng tin } \\
\text { cậy } \\
\text { TRS4. Nhà bán lẻ trực tuyến thực hiện đúng cam kết } \\
\text { TRS5. Nhà bán lẻ trực tuyến có uy tín tốt }\end{array}$ & $\begin{array}{l}\text { Knight, Choudhury, } \\
\text { Kacmar [31]. } \\
\text { Cuneyt \& Gautam, [18] } \\
\text { Tự phát triển. }\end{array}$ \\
\hline $\begin{array}{l}\text { Chuẩn chủ quan của } \\
\text { khách hàng } \\
\text { (Subjective Norm) }\end{array}$ & $\begin{array}{l}\text { SJN1. Các đánh giá/kinh nghiệm của người thân và bạn bè } \\
\text { SJN2. Các đánh giá của cộng đồng người dùng mạng } \\
\text { SJN3. Kiến thức mua sắm trực tuyến của bản thân } \\
\text { SJN4. Kinh nghiệm cá nhân về mua sắm trực tuyến }\end{array}$ & $\begin{array}{l}\text { Constantinides [10]. } \\
\text { Nandini \& Jeevananda } \\
\text { [14]. } \\
\text { Tự phát triển. }\end{array}$ \\
\hline $\begin{array}{l}\text { Thiết kế website } \\
\text { (Website Design) }\end{array}$ & $\begin{array}{l}\text { WED1. Cấu trúc website được thiết kế logic giữa trang chủ } \\
\text { (home page) và các trang nội dung (contents) } \\
\text { WED2. Website sử dụng các hiệu ứng hỗ trợ tốt cho sản phẩm } \\
\text { may mặc } \\
\text { WED3. Website có giao diện đẹp, màu sắc hài hòa } \\
\text { WED4. Website sử dụng kiểu chữ và phông chữ hợp lý } \\
\text { WED5. Nội dung các bài giới thiệu sản phẩm trên website hấp } \\
\text { dẫn }\end{array}$ & $\begin{array}{l}\text { Rosen \& Purinton [24]. } \\
\text { Porat, Liss, Tractinsky } \\
\text { [25]. } \\
\text { Cyr, Head, Larios [27]. } \\
\text { Osorno [9]. } \\
\text { Tự phát triển. }\end{array}$ \\
\hline $\begin{array}{l}\text { Sự tiện lợi của giao } \\
\text { dịch trực tuyến } \\
\text { (Usability) }\end{array}$ & $\begin{array}{l}\text { UST1. Website mua sắm trực tuyến tương thích với mọi thiết bị } \\
\text { di động UST2. Website mua sắm trực tuyến được hố trợ tốt trên } \\
\text { nhiều trình duyệt web } \\
\text { UST3. Website mua sắm trực tuyến có nhiều từ khóa (Key } \\
\text { words) giúp khách hàng dề dàng tìm kiếm, truy cập. } \\
\text { UST4. Quy trình mua hàng trực tuyến dễ dàng, thuận lợi } \\
\text { UST5. Hình thức thanh toán trực tuyến đa dạng } \\
\text { UST6. Quy trình giao hàng thuận tiện và nhanh chóng } \\
\text { UST7. Quy trình trả hàng đơn giản }\end{array}$ & $\begin{array}{l}\text { Porat, Liss, Tractinsky } \\
\text { [25]. } \\
\text { Osorno [9]. } \\
\text { Chiu \& đồng sự [32]. } \\
\text { Tự phát triển. }\end{array}$ \\
\hline $\begin{array}{l}\text { Tính tương tác khi } \\
\text { giao dịch trực tuyến } \\
\text { (Interactivity) }\end{array}$ & $\begin{array}{l}\text { INT1. Website mua sắm trực tuyến có tốc độ truy cập, điều } \\
\text { hướng (navigation) nhanh. } \\
\text { INT2. Website cung cấp cho khách hàng những trải nghiệm web } \\
\text { với mức độ cá nhân hóa cao } \\
\text { INT3. Website cung cấp cho khách hàng kênh giao tiếp } 2 \text { chiều } \\
\text { giữa nhà bán lẻ trực tuyến và khách hàng } \\
\text { INT4. Website giúp khách hàng dễ dàng trao đổi thông tin với } \\
\text { những khách hàng khác } \\
\text { INT5. Dịch vụ chăm sóc khách hàng trực tuyến tốt (e-CRM - } \\
\text { Electronic Customers Relationship Management) }\end{array}$ & $\begin{array}{l}\text { Häubl and V. Trifts [8]. } \\
\text { Ye \& đồng sự [21]. } \\
\text { Constantinides [10]. } \\
\text { Sanad [11]. } \\
\text { Tự phát triển. }\end{array}$ \\
\hline
\end{tabular}


Quyết định mua trực tuyến sản phẩm may mặc (Online purchase decision)
OPD1. Hài lòng với quyết định mua sản phẩm may mặc trực tuyến

OPD2. Sẽ tiếp tục mua trực tuyến hàng may mặc

OPD3. Sẵn lòng hướng dẫn người quen mua sắm trực tuyến

PHỤ LỤC 2A: PHÂN TÍCH NHÂN TỐ EFA CHO CÁC BIẾN ĐộC LẬP

\begin{tabular}{|l|c|c|}
\hline \multicolumn{1}{|c|}{ Chỉ tiêu } & Kết quả & So sánh tiêu chuẩn \\
\hline Tỷ lệ quy mô mẫu và số quan sát & $\mathbf{1 5 , 2 5 : \mathbf { 1 }}$ & Đạt tỷ lệ cao \\
\hline Hệ số KMO & $\mathbf{0 , 8 2 3}$ & $0,5<0,823<1$ \\
\hline Hệ số Sig của kiểm định Barlett & $\mathbf{0 , 0 0 0}$ & $0,000<0,05$ \\
\hline Tổng phương sai trích (Total Variance Explained) & $\mathbf{6 0 , 3 3 9 \%}$ & $60,339 \%>50,0 \%$ \\
\hline Hệ số Eigenvalue & $\mathbf{1 , 3 1 1}$ & $1,311>1$ \\
\hline
\end{tabular}

Nguồn: Trích kết quả xủ lý SPSS

PHỤ LỤC 2B: PHÂN TÍCH NHÂN TỐ EFA CHO BIẾN PHỤ THUỘC

\begin{tabular}{|l|c|c|}
\hline \multicolumn{1}{|c|}{ Chỉ tiêu } & Kết quả & So sánh tiêu chuẩn \\
\hline Hệ số KMO & $\mathbf{0 , 6 8 8}$ & $0,5<0,688<1$ \\
\hline Hệ số Sig của kiểm định Barlett & $\mathbf{0 , 0 0 0}$ & $0,000<0,05$ \\
\hline Tổng phương sai trích (Total Variance Explained) & $\mathbf{6 6 , 7 5 9 \%}$ & $66,759 \%>50,0 \%$ \\
\hline Hệ số Eigenvalue & $\mathbf{2 , 0 0 3}$ & $2,003>1$ \\
\hline
\end{tabular}

Nguồn: Trích kết quả xủ lý SPSS

PHỤ LỤC 3A: MA TRẬN XOAY CÁC BIẾN ĐỘC LẬP

\begin{tabular}{|c|c|c|c|c|c|c|}
\hline \multirow{2}{*}{ Mã hóa và Tên biến quan sát } & \multicolumn{6}{|c|}{ Thành phần } \\
\hline & 1 & 2 & 3 & 4 & 5 & 6 \\
\hline PER5_Sản phẩm có giá cả hợp lý so với mua tại cửa hàng & .863 & & & & & \\
\hline PER6_Sản phẩm luôn có sẵn & .841 & & & & & \\
\hline PER4_Sản phẩm có nguồn gốc, xuất xứ thương hiệu rõ ràng & .725 & & & & & \\
\hline PER1_Sản phẩm có kiểu dáng, màu sắc rất phong phú & .713 & & & & & \\
\hline PER2_Sản phẩm có đầy đủ các kích cỡ cơ bản & .693 & & & & & \\
\hline PER3_Sản phẩm có chất liệu phù hợp với chủng loại đồ & .676 & & & & & \\
\hline UST1_Website tương thích với mọi thiết bị di động & & .730 & & & & \\
\hline $\begin{array}{l}\text { UST3_Website có nhiều từ khoá giúp khách hàng dễ tìm kiếm, } \\
\text { truy cập }\end{array}$ & & .688 & & & & \\
\hline UST5_Phương thức thanh toán trực tuyến đa dạng & & .657 & & & & \\
\hline UST2_Website được hỗ trợ tốt trên nhiều trình duyệt web & & .640 & & & & \\
\hline UST4_Quy trình mua hàng trực tuyến dễ dàng, thuận lợi & & .632 & & & & \\
\hline UST7_Quy trình đổi trả sản phẩm đơn giản & & .585 & & & & \\
\hline UST6_Quy trình giao nhận sản phẩm thuận tiện, nhanh chóng & & .583 & & & & \\
\hline WED5_Nội dung bài giới thiệu sản phẩm hấp dẫn & & & .784 & & & \\
\hline WED1_Cấu trúc website được thiết kế logic & & & .728 & & & \\
\hline WED2_Website sử dụng các hiệu ứng hỗ trợ tốt cho sản phẩm & & & .714 & & & \\
\hline WED3_Website có giao diện đẹp, màu sắc hài hoà & & & .710 & & & \\
\hline WED4_Website sử dụng kiểu chữ, phông chữ hợp lý & & & .604 & & & \\
\hline INT5_Dịch vụ chăm sóc khách hàng trực tuyến tốt & & & & .896 & & \\
\hline $\begin{array}{l}\text { INT2_Website cung cấp những trải nghiệm với mức độ cá nhân } \\
\text { hoá cao }\end{array}$ & & & & .737 & & \\
\hline $\begin{array}{l}\text { INT3_Website cung cấp kênh giao tiếp hai chiều giữa nhà bán lẻ } \\
\text { và khách hàng }\end{array}$ & & & & .724 & & \\
\hline INT1_Website có tốc độ truy cập, điều hướng nhanh & & & & .719 & & \\
\hline
\end{tabular}




\begin{tabular}{|l|l|l|l|l|}
\hline $\begin{array}{l}\text { INT4_Website giúp các khách hàng dễ dàng trao đổi thông tin } \\
\text { với nhau về sản phẩm }\end{array}$ & & & .671 & \\
\hline TRS3_Thông tin về sản phẩm trên web đáng tin cậy & & & & \\
\hline TRS5_Đánh giá nhà bán lẻ trực tuyến có uy tín tốt & & & & .800 \\
\hline TRS2_Tin rằng việc thanh toán trực tuyến an toàn & & & .741 \\
\hline TRS4_Nhà bán lẻ trực tuyến thực hiện đúng cam kết & & & .713 & \\
\hline TRS1_Tin rằng thông tin cá nhân của khách hàng được bảo mật & & & .654 & \\
\hline SJN2_Tác động từ bình luận, đánh giá của cộng đồng mạng & & & .565 & \\
\hline SJN4_Khách hàng có đủ kinh nghiệm mua sắm trực tuyến & & & .750 \\
\hline $\begin{array}{l}\text { SJN1_Tác động từ đánh giá, kinh nghiệm của bạn bè và người } \\
\text { thân }\end{array}$ & & & & .738 \\
\hline SJN3_Khách hàng có đủ kiến thức mua sắm trực tuyến & & & & .641 \\
\hline
\end{tabular}

Nguồn: Trich kết quả xủ lý SPSS

PHỤ LỤC 3B: MA TRẬN THÀNH PHẦN CHO BIẾN PHỤ THUỘC

\begin{tabular}{|l|c|}
\hline \multicolumn{1}{|c|}{ Mã hóa và Tên biến quan sát } & Thành phần \\
\cline { 2 - 2 } & 1 \\
\hline OPD2_Tiếp tục mua trực tuyến sản phẩm may mặc & .830 \\
\hline OPD3_Hướng dẫn người thân và bạn bè mua sắm trực tuyến sản phẩm may mặc & .829 \\
\hline OPD1_Hài lòng quyết định mua sản phẩm may mặc trực tuyến & .792 \\
\hline
\end{tabular}

Nguồn: Trích kết quả xủ lý SPSS

PHỤ LỤC 4: MA TRẬN HỆ SỐ TƯƠNG QUAN GIŨ̉A CÁC BIẾN ĐỘC LẬP VÀ BIẾN PHỤ THUỘC

\begin{tabular}{|c|c|c|c|c|c|c|c|c|}
\hline \multicolumn{2}{|c|}{ Biến } & Y_OPD & X1_PER & X2_UST & X3_WED & X4_INT & X5_TRS & X6_SJN \\
\hline \multirow{7}{*}{$\begin{array}{l}\text { Pearson } \\
\text { Correlation }\end{array}$} & Y_OPD & 1.000 & .597 & .514 & .510 & .460 & .345 & .673 \\
\hline & X1_PER & .597 & 1.000 & .367 & .288 & .322 & .301 & .610 \\
\hline & X2_UST & .514 & .367 & 1.000 & .369 & .271 & .183 & .396 \\
\hline & X3_WED & .510 & .288 & .369 & 1.000 & .442 & .049 & .357 \\
\hline & X4_INT & .460 & .322 & .271 & .442 & 1.000 & .214 & .305 \\
\hline & X5_TRS & .345 & .301 & .183 & .049 & .214 & 1.000 & .329 \\
\hline & X6_SJN & .673 & .610 & .396 & .357 & .305 & .329 & 1.000 \\
\hline \multirow{7}{*}{ Sig. (1-tailed) } & Y_OPD & . & .000 & .000 & .000 & .000 & .000 & .000 \\
\hline & X1_PER & .000 & . & .000 & .000 & .000 & .000 & .000 \\
\hline & X2_UST & .000 & .000 & . & .000 & .000 & .000 & .000 \\
\hline & X3_WED & .000 & .000 & .000 & . & .000 & .140 & .000 \\
\hline & X4_INT & .000 & .000 & .000 & .000 &. & .000 & .000 \\
\hline & X5_TRS & .000 & .000 & .000 & .140 & .000 & . & .000 \\
\hline & X6_SJN & .000 & .000 & .000 & .000 & .000 & .000 & . \\
\hline \multirow{7}{*}{$\mathbf{N}$} & Y_OPD & 488 & 488 & 488 & 488 & 488 & 488 & 488 \\
\hline & X1_PER & 488 & 488 & 488 & 488 & 488 & 488 & 488 \\
\hline & X2_UST & 488 & 488 & 488 & 488 & 488 & 488 & 488 \\
\hline & X3_WED & 488 & 488 & 488 & 488 & 488 & 488 & 488 \\
\hline & X4_INT & 488 & 488 & 488 & 488 & 488 & 488 & 488 \\
\hline & X5_TRS & 488 & 488 & 488 & 488 & 488 & 488 & 488 \\
\hline & X6_SJN & 488 & 488 & 488 & 488 & 488 & 488 & 488 \\
\hline
\end{tabular}




\section{SẢN PHẨM MAY MẶC CỦA KHÂCH HÀNG TẠI TP. HỔ CHÍ MINH}

PHỤ LỤC 5: PHÂN TÍCH SÂU ANOVA (KIỂM ĐỊNH TAMHANE)

\begin{tabular}{|c|c|c|c|c|c|c|}
\hline \multirow{2}{*}{$\begin{array}{l}\text { (I) Thu } \\
\text { nhập trung } \\
\text { bình }\end{array}$} & \multirow[t]{2}{*}{ (J) Thu nhập trung bình } & \multirow{2}{*}{$\begin{array}{c}\text { Mean } \\
\text { Difference (I- } \\
\text { J) }\end{array}$} & \multirow{2}{*}{$\begin{array}{l}\text { Std. } \\
\text { Error }\end{array}$} & \multirow[t]{2}{*}{ Sig. } & \multicolumn{2}{|c|}{$95 \%$ Confidence Interval } \\
\hline & & & & & Lower Bound & Upper Bound \\
\hline \multirow{5}{*}{$\begin{array}{l}\text { Dưới } 5 \\
\text { triệu đồng }\end{array}$} & Từ 5 đến dưới 10 triệu đồng &,$- 30500^{*}$ &, 08431 & ,006 &,- 5549 &,- 0551 \\
\hline & Từ 10 đến dưới 18 triệu đồng &,$- 31549^{*}$ & 08586 &, 005 &,- 5700 &,- 0610 \\
\hline & Từ 18 đến dưới 32 triệu đồng &,$- 38659^{*}$ & 08922 &, 000 &,- 6514 &,- 1218 \\
\hline & Từ 32 đến dưới 52 triệu đồng &,- 31087 & ,14227 & ,395 &,- 7454 & ,1237 \\
\hline & Trên 52 triệu đồng &,- 59158 & ,50422 & 1,000 & $-80,2433$ & 79,0601 \\
\hline \multirow{5}{*}{$\begin{array}{l}\text { Từ } 5 \text { đến } \\
\text { dưới } 10 \\
\text { triệu đồng }\end{array}$} & Dưới 5 triệu đồng & ,30500* &, 08431 & ,006 &, 0551 & 5549 \\
\hline & Từ 10 đến dưới 18 triệu đồng &,- 01049 & 07753 & 1,000 &,- 2395 & 2186 \\
\hline & Từ 18 đến dưới 32 triệu đồng &,- 08159 & 08123 & ,997 &,- 3223 & ,1592 \\
\hline & Từ 32 đến dưới 52 triệu đồng &,- 00587 & ,13741 & 1,000 &,- 4279 & ,4161 \\
\hline & Trên 52 triệu đồng &,- 28657 & ,50286 & 1,000 & $-83,9947$ & 83,4215 \\
\hline \multirow{5}{*}{$\begin{array}{l}\text { Từ } 10 \text { đến } \\
\text { dưới } 18 \\
\text { triệu đồng }\end{array}$} & Dưới 5 triệu đồng & ,31549* & 08586 & ,005 &, 0610 & 5700 \\
\hline & Từ 5 đến dưới 10 triệu đồng & ,01049 & 07753 & 1,000 &,- 2186 & 2395 \\
\hline & Từ 18 đến dưới 32 triệu đồng &,- 07110 &, 08284 & ,999 &,- 3166 &, 1744 \\
\hline & Từ 32 đến dưới 52 tri & ,00462 & 13836 & 1,000 &,- 4198 & ,4290 \\
\hline & Trên 52 triệu đồng &,- 27608 & ,50313 & 1,000 & $-83,1747$ & 82,6226 \\
\hline \multirow{5}{*}{$\begin{array}{l}\text { Từ } 18 \text { đến } \\
\text { dưới } 32 \\
\text { triệu đồng }\end{array}$} & Dưới 5 triệu đồng & ,38659* & ,08922 &, 000 &, 1218 & ,6514 \\
\hline & Từ 5 đến dưới 10 triệu đồng & ,08159 &, 08123 & ,997 &,- 1592 & ,3223 \\
\hline & Từ 10 đến dưới 18 triệu đồng & 07110 &, 08284 & ,999 &,- 1744 & ,3166 \\
\hline & Từ 32 đến dưới 52 triệu đồng & ,07572 &, 14047 & 1,000 &,- 3542 &, 5056 \\
\hline & Trên 52 triệu đồng &,- 20498 & ,50371 & 1,000 & $-81,3422$ & 80,9323 \\
\hline \multirow{5}{*}{$\begin{array}{l}\text { Từ } 32 \text { đến } \\
\text { dưới } 52 \\
\text { triệu đồng }\end{array}$} & Dưới 5 triệu đồng & ,31087 & ,14227 & 395 &,- 1237 & ,7454 \\
\hline & Từ 5 đến dưới 10 triệu đồng & 00587 & ,13741 & 1,000 &,- 4161 & 4279 \\
\hline & Từ 10 đến dưới 18 triệu đồng &,- 00462 & , 13836 & 1,000 &,- 4290 &, 4198 \\
\hline & Từ 18 đến dưới 32 triệu đồng &,- 07572 & , 14047 & 1,000 &,- 5056 &, 3542 \\
\hline & Trên 52 triệu đồng &,- 28070 & ,51576 & 1,000 & $-54,0095$ & 53,4481 \\
\hline \multirow{5}{*}{$\begin{array}{l}\text { Trên } 52 \\
\text { triệu đồng }\end{array}$} & Dưới 5 triệu đồng & ,59158 & ,50422 & 1,000 & $-79,0601$ & 80,2433 \\
\hline & Từ 5 đến dưới 10 triệu đồng & 28657 &, 50286 & 1,000 & $-83,4215$ & 83,9947 \\
\hline & Từ 10 đến dưới 18 triệu đồng & 27608 &, 50313 & 1,000 & $-82,6226$ & 83,1747 \\
\hline & Từ 18 đến dưới 32 triệu đồng & ,20498 & ,50371 & 1,000 & $-80,9323$ & 81,3422 \\
\hline & Từ 32 đến dưới 52 triệu đồng & ,28070 &, 51576 & 1,000 & $-53,4481$ & 54,0095 \\
\hline
\end{tabular}

Nguồn: Trich kết quả xủ lý SPSS 